
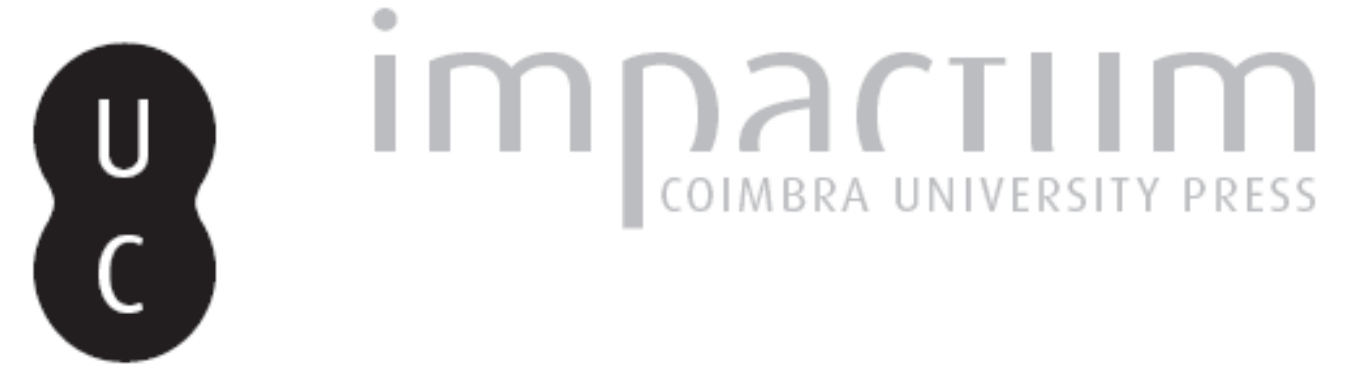

\title{
A genealogia cadmeia em Tebas
}

\section{Autor(es): Braga, Alessandro Eloy}

Publicado por: Imprensa da Universidade de Coimbra

URL persistente:

URl:http://hdl.handle.net/10316.2/41444

DOI:

DOI:https://doi.org/10.14195/0872-2110_60_1

Accessed : $\quad$ 26-Apr-2023 09:17:27

A navegação consulta e descarregamento dos títulos inseridos nas Bibliotecas Digitais UC Digitalis, UC Pombalina e UC Impactum, pressupõem a aceitação plena e sem reservas dos Termos e Condições de Uso destas Bibliotecas Digitais, disponíveis em https://digitalis.uc.pt/pt-pt/termos.

Conforme exposto nos referidos Termos e Condições de Uso, o descarregamento de títulos de acesso restrito requer uma licença válida de autorização devendo o utilizador aceder ao(s) documento(s) a partir de um endereço de IP da instituição detentora da supramencionada licença.

Ao utilizador é apenas permitido o descarregamento para uso pessoal, pelo que o emprego do(s) título(s) descarregado(s) para outro fim, designadamente comercial, carece de autorização do respetivo autor ou editor da obra.

Na medida em que todas as obras da UC Digitalis se encontram protegidas pelo Código do Direito de Autor e Direitos Conexos e demais legislação aplicável, toda a cópia, parcial ou total, deste documento, nos casos em que é legalmente admitida, deverá conter ou fazer-se acompanhar por este aviso.




COIMBRA • 2015

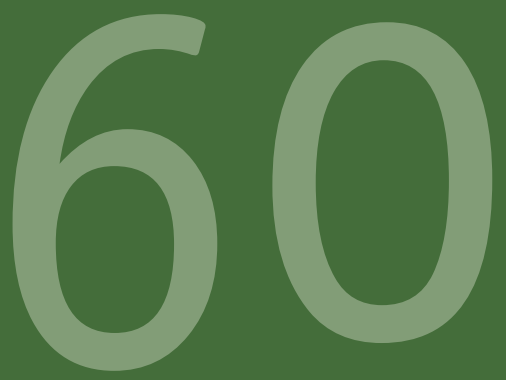

\title{
BOLETIM DE
}

\section{ESTUDOS CLÁSSICOS}

\author{
ASSOCIAÇÃO \\ PORTUGUESA \\ DE ESTUDOS \\ CLÁSSICOS \\ INSTITUTO \\ DE ESTUDOS \\ CLÁSSICOS
}




\title{
A GENEALOGIA CADMEIA EM TEBAS
}

\section{THE CADMEAN GENEALOGY IN THEBES}

\author{
ALESSANDRO ELOY BRAGA \\ CECH - UNIVERSIDADE DE COIMBRA \\ alessandrobragabr@gmail.com
}

Resumo: Segundo a mitologia grega, Cadmo foi o fundador de Tebas. Sua linhagem real reinou soberana sobre a cidade mesmo diante de uma longa sequência de infortúnios representados nas sete tragédias do ciclo tebano que chegaram até nós, além de outras com as quais não tivemos contato. Este artigo apresenta a sistematização da genealogia de Cadmo em Tebas, ou genealogia cadmeia, a partir do estudo em conjunto destas sete tragédias.

Palavras-chave: Genealogia cadmeia; Cadmo; autoctonia; Tebas; tragédias; ciclo tebano.

Abstract: According to Greek mythology, Cadmus was the founder of Thebes. His royal line sovereignly reigned over the city in the face of a long string of misfortunes represented in the seven tragedies of the Theban cycle that survived, as well as other works with which we had no contact. This article presents the systematization of the genealogy of Cadmus in Thebes, or the cadmean genealogy, from the study of these seven tragedies together.

Keywords: The Cadmean genealogy; Cadmus; autochthony; Thebes; Tragedies; Theban cycle.

A história que compreende a trágica descendência de Cadmo, protagonista tebano de autoctonia, a exemplo de muitos outros mitos gregos, 
apresenta diferentes versões que, provavelmente, foram se formando com a mistura dos povos que constituíram os Gregos, pelo andar da história e pelos vários interesses que moldaram estes mitos ao longo dos anos. Não seria, assim, um equívoco presumir que os tragediógrafos também tiveram conhecimento de versões diferentes, da mesma maneira que também inseriram outras modificações, ou fizeram releituras, para atender alguns interesses da obra de arte, sem, no entanto, distanciarem-se de um tronco fundamental que está na sua a base.

A genealogia que aqui propomos para Cadmo foi pensada e organizada a partir das relações familiares e consanguíneas identificadas na leitura conjunta das sete tragédias do ciclo tebano, acrescentando-se algumas informações retiradas de estudos dos historiadores do mito Grimal ${ }^{1,}$ Graves $^{2}$ e Brandão ${ }^{3}$, quando os textos das tragédias não conseguiam preencher certas lacunas de parentesco. Ainda assim, algumas interrogações persistiram, as quais não foram empecilho para a formulação do que denominamos de 'genealogia cadmeia'.

Foi possível, então, elaborar uma árvore genealógica para o oikos de Cadmo, compreendendo o período que se estende da semeadura dos dentes do dragão - o mito da autoctonia - até a morte dos filhos de Édipo e dos filhos de Creonte ${ }^{4}$. A formação da genealogia contemplou aqueles nomes que aparecem entre as sete peças como personagens relacionados ao 'processo trágico' da família ${ }^{5}$, seja como personagens ou

${ }^{1}$ Cf. Grimal 2005.

${ }^{2}$ Cf. Graves 2005.

${ }^{3}$ Cf. Brandão 2010.

${ }^{4}$ Apesar de Grimal 2005: 66 e Brandão 2010: 244 apresentarem quadros que sintetizam a linhagem de Cadmo, entendemos que a versão que aqui apresentamos preenche lacunas que ambos os estudiosos deixaram ao estabelecer tal genealogia. Além disso, nesta genealogia, assumimos também os Spartoi como descendentes diretos de Cadmo, pois estes são fruto de sua semeadura no solo da Beócia, o que não ocorre nas versões de Grimal e Brandão.

${ }^{5}$ A percepção e a concepção de ideia de um 'processo trágico' que compreende a história de infortúnios da linhagem de Cadmo em Tebas é desenvolvida por Braga 2015. Tal processo é constituído pela sequência de mazelas experimentadas pela linhagem 
apenas na forma de referências, bem como outros nomes que aparecem nos estudos de Grimal, Graves e Brandão como membros da linhagem.

Nesta genealogia proposta, Cadmo foi o miastor fundador de uma cadeia desgraçada de reis, numa cidade cujo solo foi amaldiçoado pela nemesis de Ares ${ }^{6}$. Da semeadura do fundador nascem os Spartoi, entre eles Equíon, que desposa Agave, filha do casamento de Cadmo com a deusa Harmonia7 . Da união entre dois descendentes do mesmo pai, nasceu Penteu, neto do Tírio, que se tornou soberano da cidade quando o avô decidiu distanciar-se do poder ${ }^{9}$. Após receber de Cadmo o cetro de Tebas, o novo tirano empreendeu um combate ao culto de Dioniso, seu primo, nascido da união de Zeus e Sêmele ${ }^{10}$, também filha de Cadmo. 0 conflito resultou no esquartejamento de Penteu pela ação da própria mãe que se encontrava em um transe, sob as influências de Dioniso. Após o filicídio, Agave permaneceu viva e exilou-se para expiar suas ações. Depois do assassinato do neto, Cadmo e Harmonia abandonaram a cidade e exilaram-se na região da Ilíria, onde o Tírio tornou-se rei

real de Tebas e que afetam diretamente os habitantes da cidade. Seu início se dá no momento em que é forjado o mito de autoctonia protagonizado por Cadmo e tem seu fim com a morte e Hémon e Meneceu, filhos de Creonte e últimos descendentes da genealogia cadmeia.

${ }^{6}$ Esta condição de Cadmo como miastor e o problema da maldição de Ares que recai sobre a linhagem do fundador de Tebas são apresentados e desenvolvidos por Braga 2015. Desta maldição resulta o 'processo trágico' que assola Tebas e os reis cadmeus.

${ }^{7}$ Sobre o casamento de Cadmo e Harmonia, cf. Hesíodo (Theog. 937).

${ }^{8}$ Consideramos os Spartoi também como filhos de Cadmo, por ter sido o Tírio aquele que plantou as sementes do dragão na terra da Beócia, simbolizando o homem fertilizando um ventre feminino. Destas sementes nasceram os primeiros autochthones tebanos, os quais, imediatamente, tornaram-se também as primeiras vítimas da maldição vingativa de Ares, restando apenas cinco deles após um violento fratricídio. Desta maneira, o matrimônio entre Agave e Equíon torna-se uma união entre irmãos que descendem do mesmo pai.

${ }^{9} \mathrm{O}$ tempo da tirania de Penteu sobre Tebas, tendo ainda Cadmo ao seu lado, é retratado por Eurípides em As Bacantes.

${ }^{10}$ Sobre a união de Zeus e Sêmele e o nascimento de Dioniso, cf. Hesíodo (Theog. 940-943). 
mais uma vez. Após muitas conquistas e um recomeço de vida repleto de honrarias, o casal foi conduzido para os Campos Elísios sem passar pelo sofrimento da morte.

Além de Equíon, um outro dos cinco Spartoi sobreviventes do fratricídio, cujo nome não é citado nas tragédias nem aparece nos estudos de Grimal e Graves, tem um papel importante na composição da linhagem de Cadmo. Este 'anônimo' deu início a outro ramo da linhagem, de onde descende Meneceu, pai de Creonte e Jocasta ${ }^{11}$.

Polidoro, que não é mencionado em nenhuma das tragédias, foi o único filho e herdeiro de Cadmo, e teria assumido o trono da cidade após o exílio do pai e a morte de Penteu. Depois de casar-se com Nicteide, filha de Ctônio, outro dos cinco Spartoi ${ }^{12}$, teve como filho Lábdaco. Da morte de Polidoro nada encontramos de muito concreto, apenas que morrera quando Lábdaco ainda era uma criança com cerca de um ano de idade ${ }^{13}$. Lábdaco continuou a luta de Penteu contra Dioniso e também foi morto por bacantes. Lábdaco foi pai de Laio e avô de Édipo.

${ }^{11}$ Grimal 2005: 302 relata que há ainda uma versão do mito de Meneceu em que este seria filho de Óclaso, que por sua vez seria filho de Penteu e, assim, descenderia direto de Cadmo. Contudo, as referências feitas à linhagem em As Fenícias (942-944) e em Os Sete contra Tebas (474) não confirmam essa possibilidade, mas apenas a descendência dos Spartoi. Logo, parece-nos que não foi esta versão da ligação com Penteu aquela que teria sido adotada pelos tragediógrafos.

${ }^{12}$ Aos outros dois Spartoi sobreviventes do fratricídio, nenhuma menção é feita na literatura.

${ }^{13}$ Brandão 2010: 246 observa que, diante da morte de Polidoro, e tendo em vista a tenra idade de Lábdaco, herdeiro natural do cetro, o trono de Tebas passa a ser ocupado de forma interina por Nicteu, pai de Nicteide (também conhecida por Nicteis ou Antíope), esposa de Ctônio, um Spartós. 


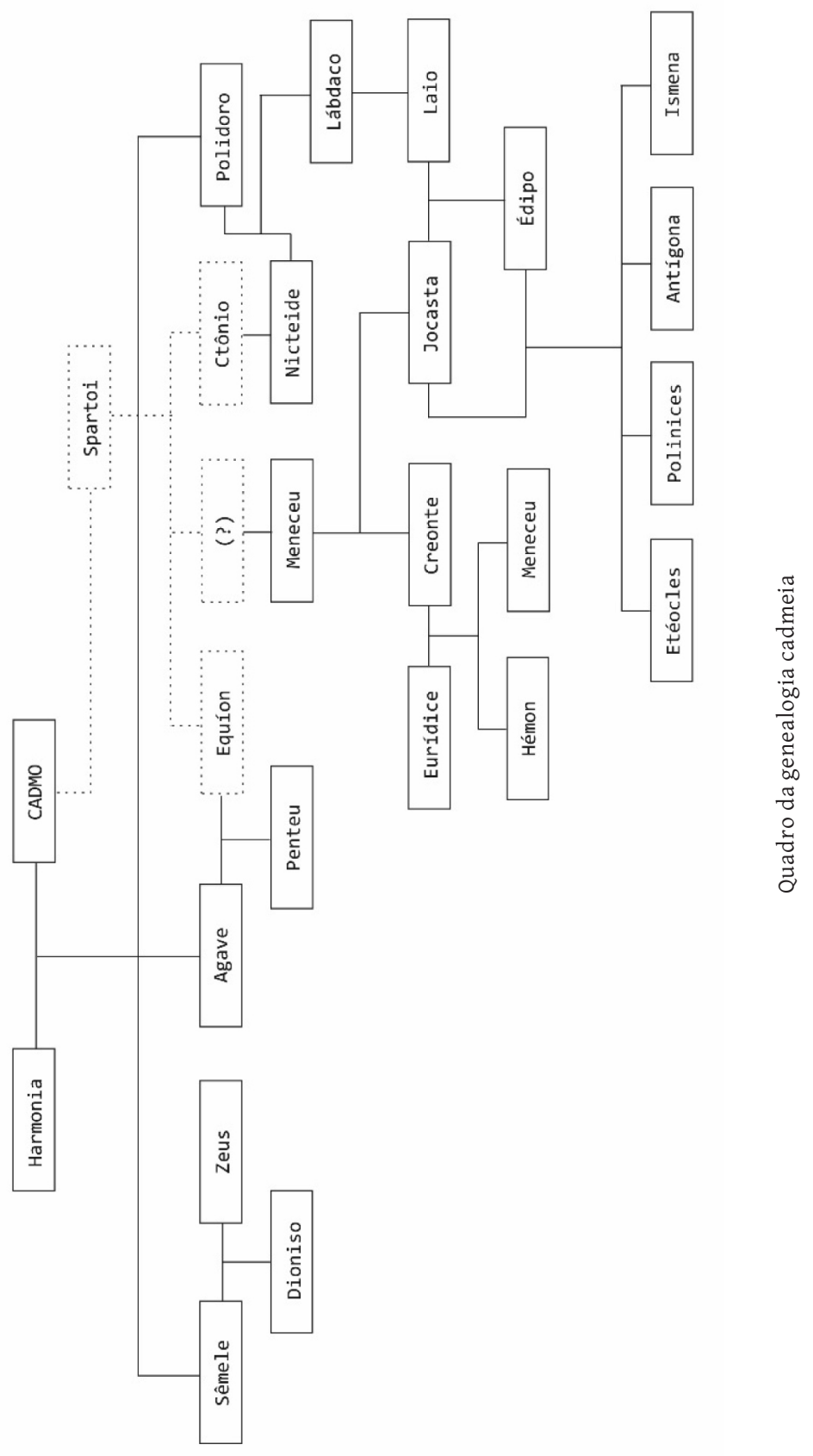


Laio casou-se com Jocasta ${ }^{14}$. Do matrimônio de Laio e Jocasta nasceu Édipo, que, a fim de evitar a realização do oráculo que predisse o parricídio e o incesto entre os três, é abandonado e entregue pelos pais para ser morto por um servo, que poupa a vida da criança para ser adotada pelos reis de Corinto. Adulto, Édipo retornou para Tebas. No caminho de sua jornada, matou Laio, e, ao chegar à cidade e salvá-la da Esfinge, desposou Jocasta, como prêmio pelos seus feitos, e com ela teve quatro filhos: Etéocles, Polinices, Antígona e Ismena, confirmando, sem consciência de que havia assassinado o pai e desposado a mãe, a previsão do oráculo. Ao ser revelada a verdade, Édipo arrancou seus próprios olhos e passou anos recluso a expiar os sofrimentos resultantes de suas ações. Jocasta suicidou-se ${ }^{15}$. Édipo, já velho, foi exilado pelo filho Polinices. Ao chegar a Colono, recebeu a proteção e uma nova cidadania na Ática e lá foi conduzido ao mundo dos mortos sem passar pelo sofrimento da morte, como ocorreu com seu antepassado $\mathrm{Cadmo}^{16}$.

Etéocles e Polinices morreram em um fratricídio ao disputarem o trono de Tebas ${ }^{17}$. Antígona suicidou-se, após ser aprisionada por Creonte, por oferecer sepultura a seu irmão Polinices, condenado a insepulto pelo tio tirano após tentar invadir a cidade. Ismena permaneceu viva.

${ }^{14}$ Filha de Meneceu, Jocasta, segundo Brandão 2010: 248, é um nome que aparece pela primeira vez em Rei Édipo de Sófocles. Pela tradição homérica (Od. 10. 271), o nome da esposa de Laio e mãe de Édipo era Epicasta.

${ }^{15}$ Em Rei Édipo (1238-1251), Jocasta suicida-se após revelada a verdade sobre sua relação com Édipo. Em As Fenícias, Jocasta havia sobrevivido ao sofrimento de saber-se esposa do próprio filho e mãe de seus netos, mas não suporta a dor de ver seus dois filhos cometerem o fratricídio (1454-1459) e comete o suicídio ao vê-los mortos.

${ }^{16}$ Este é o mito contado na versão de Sófocles em Rei Édipo e Édipo em Colono, em que o filho de Laio dirige-se para o mundo dos mortos antes de ocorrer a luta entre os filhos. Na versão de Eurípides, em As Fenícias, Édipo ainda está vivo quando do fratricídio e, após presenciar o fato, é exilado por Creonte.

${ }^{17}$ Este fratricídio é contado em Os Sete contra Tebas de Ésquilo e em As Fenícias de Eurípides, que faz mais uma vez referência ao fato em As Suplicantes. 
Creonte havia se casado com Eurídice e juntos tiveram dois filhos: Hémon e Meneceu, este último mencionado em Os Sete contra Tebas pelo nome de Megareu. Ambos cometeram suicídio ${ }^{18}$. Eurídice suicidou-se, após saber da morte de Hémon. Creonte permaneceu vivo, mas destruído pela dor de perder os filhos e a esposa por causa de suas próprias ações tirânicas.

O estabelecimento de uma genealogia mais diretamente ligada à sucessão das ações que compõem as sete tragédias do ciclo tebano contribui sobremaneira para uma leitura mais clara da sequência de infortúnios que recaiu sobre a linhagem real de Cadmo, porque demonstra que todos os seus descendentes que reinaram sobre a cidade tornaram-se objeto de uma maldição, a qual, segundo demonstrado por Braga ${ }^{19}$, teria sido infligida por Ares, como vingança pela morte de seu filho, o dragão assassinado por Cadmo; ação essencial para o mito tebano de autoctonia. A morte da fera teria poluído o fundador de Tebas com um miasma que passaria a poluir também o solo da Beócia e, por conseguinte, toda a sua linhagem nele nascida, condenada a perecer tragicamente por seus próprios atos na forma do fratricídio, do parricídio, do filicídio e do suicídio. A cura para tal poluição dar-se-ia apenas pelo fim da linhagem cadmeia, da qual Creonte tornou-se o último homem, como relatam Antígona de Sófocles e As Fenícias de Eurípides.

\footnotetext{
${ }^{18} \mathrm{Na}$ versão do mito de Creonte contada por Sófocles em Antígona, o tirano teve apenas um filho com Eurídice, de nome Hémon, que teria sido noivo de Antígona. Há uma versão do mito de Hémon, em que o jovem teria sido devorado pela Esfinge que aterrorizava Tebas e foi derrotada por Édipo. Segundo esta versão, Creonte, que ocupava o trono tebano após a morte de Laio, por ser o herdeiro mais próximo, motivado pelo desejo de vingança, teria prometido o trono da cidade para aquele que conseguisse derrotar a Esfinge e libertar a cidade de seus males - vide Grimal 2005: 203, na tradução de Jabouille.
}

${ }^{19} \mathrm{Cf}$. Braga 2015. 


\section{BIBLIOGRAFIA}

\section{EDIÇÕES, TRADUÇÕES, COMENTÁRIOS}

Ésquilo, Os Sete contra Tebas. Salvador, E. L. trad. (2006) Universidade de Campinas. [Dissertação de Mestrado]

Eurípides, As Bacantes. Pereira, M. H. da Rocha trad. (2014) Lisboa.

-, As Suplicantes. Ferreira, J. R. trad. (2012) Porto Alegre.

-, As Fenícias. Alves, M. S. trad. (1975) Coimbra.

Hesíodo, Teogonia: a origem dos deuses. Torrano, J. trad. (2009) São Paulo.

Homero, Odisseia. Lourenço, F. trad. (2012) Lisboa.

Sófocles, Rei Édipo. Fialho, M. C. trad. (2014) Lisboa.

-, Antígona. Pereira, M. H. da Rocha trad. (2012) Lisboa.

-, Édipo em Colono. Fialho, M. C. trad. (1996) Lisboa.

\section{ESTUDOS}

Braga, Alessandro Eloy (2015), As sementes de Cadmo: autoctonia, miasma, nemesis e o trágico nas tragédias do ciclo tebano. Universidade de Coimbra. [Tese de Doutoramento]

Graves, Robert, Os Mitos Gregos. Branco, F. trad. (2005), Lisboa.

Grimal, Pierre, Dicionário da Mitologia Grega e Romana. Jabouille, V. trad. (2005, $5^{\mathrm{a}}$ ed.), Rio de Janeiro.

Brandão, Junito de Souza, “Os Labdácidas: o Mito de Édipo”. In Mitologia Grega Vol. III, (2010, 17ª ed.). Petrópolis-RJ. 